\title{
Abdominal malrotation overlooked at extensive cross-sectional imaging and leading to life- threatening gastrointestinal bleeding
}

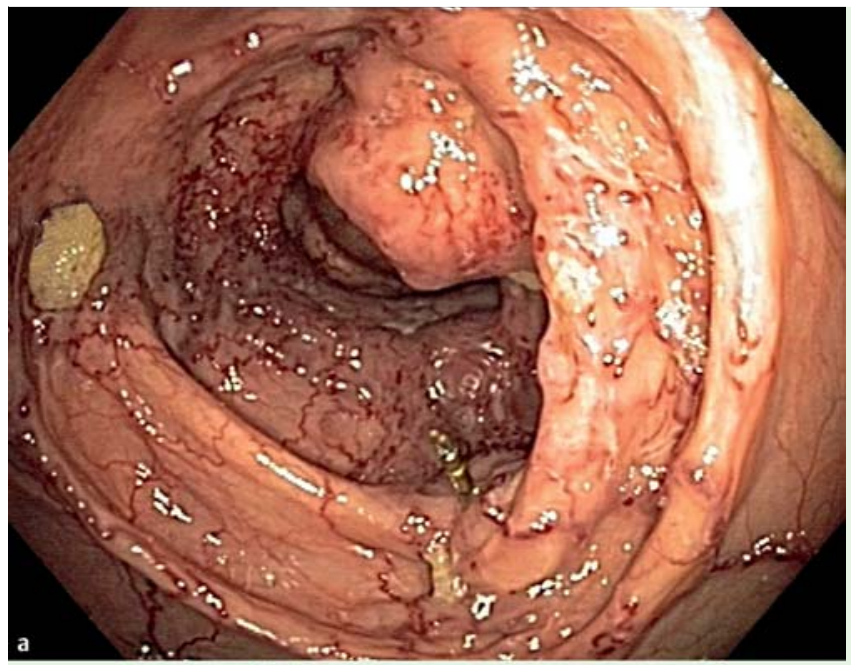

Fig. 1 a Endoscopic view of abnormal changes in the cecum of a 34-year-old woman with recurrent episodes of abdominal discomfort since early childhood, now presenting with severe anemia. b Abnormal changes in the ascending colon.

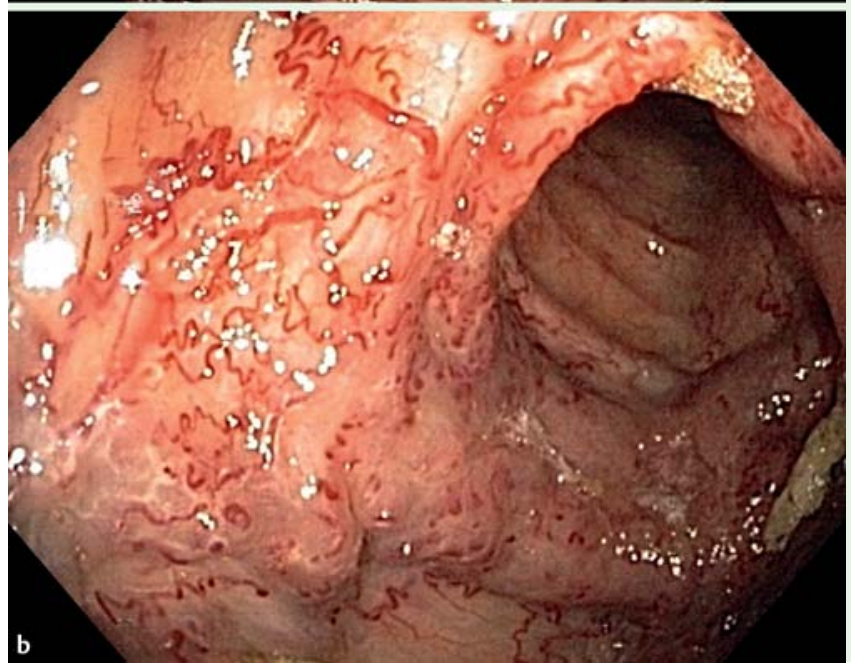

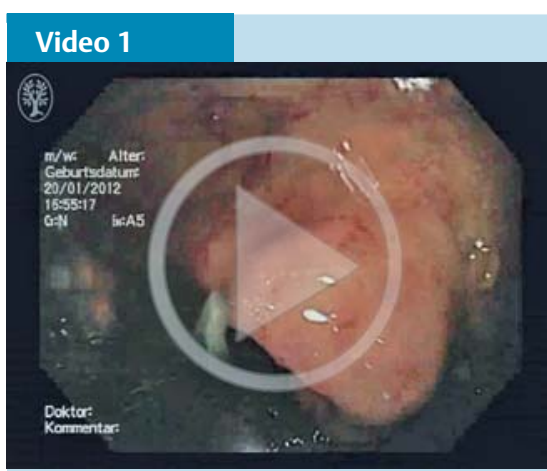

Endoscopy showing abnormal alterations in the cecum and ascending colon of a 34-year-old woman with recurrent abdominal discomfort since childhood, now presenting with severe anemia.

diagnosis of angiodysplasia. Re-evaluation of the cross-sectional imaging - MRE $(\bullet$ Fig. 2a) and computed tomography ( $\bullet$ Fig. 2b) - raised the possibility of abdominal malrotation. Laparoscopy confirmed the diagnosis, and a curative right hemicolectomy was performed. During 3years of follow-up, the patient experienced no abdominal discomfort, and her hemoglobin levels were consistently normal.

In conclusion, we present a case in which abdominal malrotation was visualized by extensive cross-sectional imaging. The malrotation resulted in compression of the mesenteric vessels with recurrent abdominal pain and, ultimately, lifethreatening bleeding. Strikingly, the malrotation was detected only after focused re-evaluation of the initial radiological work-up. There are very few reports of abdominal malrotation as a cause of gastrointestinal bleeding in adults $[1,2]$. However, based on the difficulties encountered during the diagnostic work-up of this patient, we think that awareness of the disease and its endoscopic presentation is extremely important.

Endoscopy_UCTN_Code_CCL_1AD_2AJ

Competing interests: None 


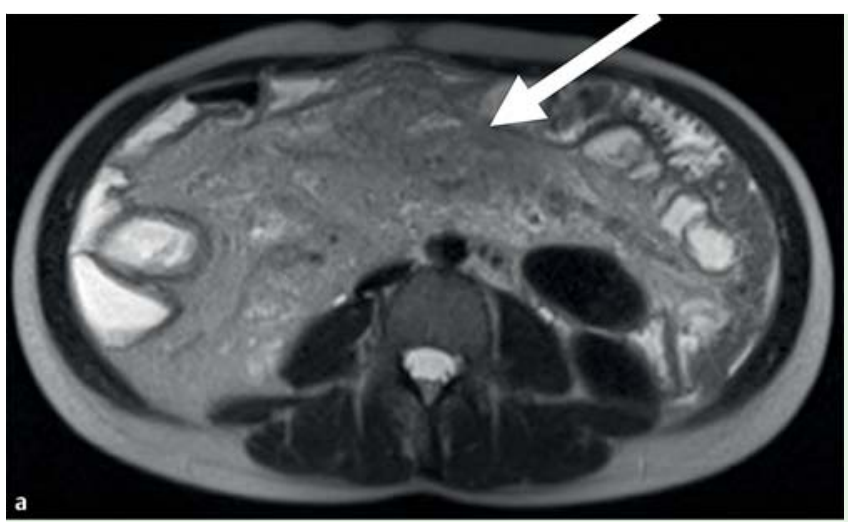

Fig. 2 Cross-sectional images suggesting abdominal malrotation (arrows). a Magnetic resonance enterography. $\mathbf{b}$ Computed tomography.

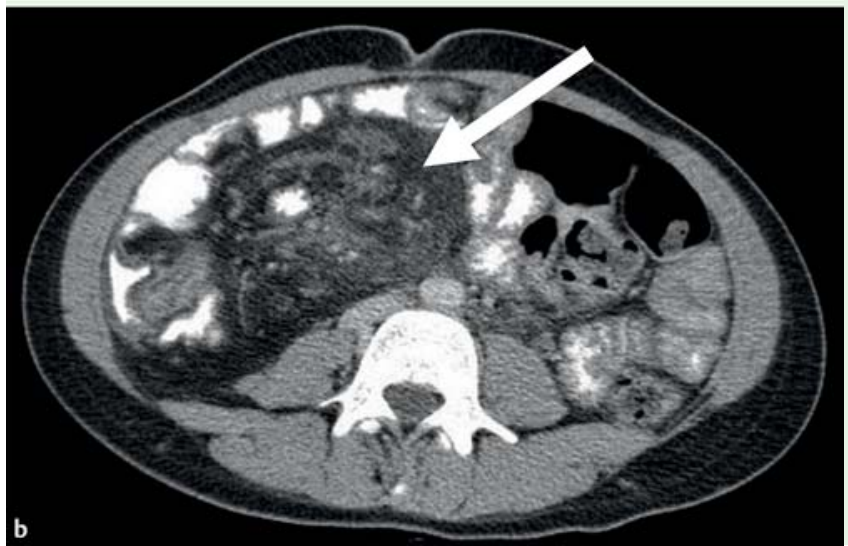

Alexander Arlt' ${ }^{1}$, Dörthe Schuldt ${ }^{1}$, Susanna Nikolaus ${ }^{1}$, Clemens Schafmayer $^{2}$, Witig von Schoenfels ${ }^{2}$, Stefan Schreiber ${ }^{1}$, Mark Ellrichmann ${ }^{1}$

${ }^{1}$ Department of Internal Medicine I, University Hospital Schleswig-Holstein, Kiel, Germany

2 Department of General and Thoracic Surgery, University Hospital SchleswigHolstein, Kiel, Germany

\section{References}

1 Palmer OP, Rhee HH, Park WG et al. Adult intestinal malrotation: when things turn the wrong way. Dig Dis Sci 2012; 57: $284-$ 287

2 Simpson S, Hollinshead J, Katelaris PH. Idiopathic localized dilatation of the ileum. A rare cause of gastrointestinal haemorrhage in an adult. J Gastroenterol Hepatol 1998; 13: $1234-1236$

\section{Bibliography}

DoI http://dx.doi.org/

10.1055/s-0034-1393651

Endoscopy 2015; 47: E639-E640

(c) Georg Thieme Verlag KG

Stuttgart · New York

ISSN 0013-726X

\section{Corresponding author}

\section{Alexander Arlt, MD}

Department of Internal Medicine I

University Hospital Schleswig-Holstein,

Campus Kiel

24105 Kiel

Germany

Fax: +49-431-5971302

aarlt@1med.uni-kiel.de 